\title{
Parisognoriste, a new genus of Lygistorrhinidae (Diptera: Sciaroidea) from the Oise amber with redescription of Palaeognoriste Meunier
}

\author{
Vladimir Blagoderov ${ }^{1, \dagger}$, Heikki Hippa ${ }^{2, \ddagger}$, André $\mathrm{Nel}^{3, \S}$
}

I Department of Entomology, The Natural History Museum, Cromwell Road, London, SW7 5BD, UK 2 Swedish Museum of Natural History, P.O.Box 50007, S-10405 Stockholm, Sweden 3 CNRS-UMR 7205, Entomologie, Muséum National d'Histoire Naturelle, 45 rue Buffon, F-75005 Paris, France

† urn:lsid:zoobank.org:author:EE802420-57F5-4285-89B3-282AB9F69894

†urn:lsid:zoobank.org:author:546524AD-3BD1-4830-842F-EEEE7DF4799B

§ urn:lsid:zoobank.org:author:98DF555A-16A0-4073-871C-E38BB506C676

Corresponding author: Vladimir Blagoderov (v.blagoderov@nhm.ac.uk)

Academic editor: Chris Thompson | Received 1 June 2010 | Accepted 8 June 2010 | Published 30 June 2010

urn:lsid:zoobank.org:pub:D3D0A515-1A8F-4F50-804D-B73DA4005731

Citation: Blagoderov V, Hippa H, Nel A (2010) Parisognoriste, a new genus of Lygistorrhinidae (Diptera, Sciaroidea) from the Oise amber with redescription of Palaeognoriste Meunier. ZooKeys 50: 79-90. doi: 10.3897/zookeys.50.506

\begin{abstract}
A new genus and a new species of Lygistorrhinidae, Parisognoriste eocenica is described from the Eocene Oise amber of the Paris Basin. Palaeognoriste sciariforme Meunier, 1904 and Palaeognoriste affine Meunier, 1912 are re-described. Lectotypes are designated for both species of Palaeognoriste. The phylogenetic positions of the new genus and Palaeognoriste Meunier are discussed. The paper is an example demonstrating a new approach in cybertaxonomy including automatic generation of manuscript within Virtual Research Environment (Scratchpads), semantic enhancements, and parallel release of the publication on paper and on-line accompanied with registration of new taxa with ZooBank.
\end{abstract}

\section{Keywords}

taxonomy, new taxa, phylogeny, fossil resin, Eocene

\section{Introduction}

The Le Quesnoy locality, near Houdancourt (Oise), has yielded fossiliferous amber associated with abundant plant remains and a diverse vertebrate fauna in sediments (Nel

Copyright Vladimir Blagoderov et al. This is an open access article distributed under the terms of the Creative Commons Attribution License, which permits unrestricted use, distribution, and reproduction in any medium, provided the original author and source are credited. 
et al. 2004). Its age is lowermost Eocene and the infrared spectra (KBr) of Le Quesnoy and Baltic ambers are very different, with that of the former more similar to the Recent Hymenaea copal. Only a small fraction of the insect genera and even fewer species of the Oise amber (also known sometimes as Paris Basin amber) are also present in Baltic amber (Nel et al. 2005). The palaeoclimate of Oise amber corresponds to the maximum global warming of the Palaeocene-Eocene boundary, which could partly explain the differences of it's fauna from the fauna of Baltic amber.

A number of specimens of Sciaroidea were discovered in the Oise amber, of which perhaps the most interesting are several specimens of a lygistorrhinid fly. The purpose of the present paper is to describe this new taxon and discuss its systematic position. Superficially, it is similar to Palaeognoriste Meunier, the two species of which were described from Baltic amber in the early 20th century. Meunier (1904) described the first, Palaeognoriste sciariforme, from the Königsberg collection of Baltic amber, based on a male and a female found in two separate pieces of amber, and erected a new genus, Palaeognoriste, to accommodate it. Later, he described another species, $P$. affine, based on two specimens found in copula in a single piece of amber (Meunier 1912). Unfortunately, both descriptions were very short and vague. To adequately describe the new genus from the Oise amber and to compare it with known fossil and recent taxa it was necessary to re-describe both species of Palaeognoriste and designate lectotypes for both species.

\section{Material and methods}

The piece of Oise amber containing three female specimens of the new species was cut in two for better observation and polished on a slab of diatomite. Type material of both species of Palaeognoriste was also studied. Fortunately, the specimens were not lost during World War II, as many of Meunier's other types were. The type of P. affine was kept in Geowissenschaftlisches Zentrum der Georg-August-Universität, Göttingen. In 2007, VB found syntypes of P. sciariforme in the Laboratory of Entomology, Muséum national d'Histoire naturelle, Paris, where they had been borrowed by the late Prof. L. Matile several years previously. Digital photography was undertaken using Zeiss Axioskop compound microscope and Canon EOS450D camera, the resulting images then being combined to increase depth of field using Helicon Focus v. 4.77 software. All images are available at Fungus Gnats Online website (www.sciaroidea.info).

The descriptions of new taxa and redescription of known species were prepared on the Fungus Gnats Online Scratchpad as an initial stage of testing online taxonomic workflow as described in Blagoderov et al. (2010). The paper has been semantically tagged and enhanced using the Pensoft Mark Up Tool (PMT) which is based on the US National Library of Medicine's DTD (Document Type Definitions) TaxPub extension (http://sourceforge.net/projects/taxpub). The final XML output of the paper has been archived in PubMedCentral, a PDF uploaded in the Biodiversity Heritage Library (BHL), and all revised species registered in ZooBank (Penev et al. 2010). 


\section{Systematics}

\section{Parisognoriste gen. $\mathbf{n}$.}

urn:lsid:zoobank.org:act:D95A5DF3-9A27-474D-A504-AE90BD99F388

\section{Type species. Parisognoriste eocenica sp. n.}

Diagnostic description. Small lygistorrhinid flies. Proboscis small, about 1/3 of the height of head, palpus four-segmented, much longer than proboscis. Ocelli three, median ocellus smaller than the lateral ocelli. Scutum moderately convex, laterotergite bare. Vestiture of tibiae in rows on apical part. Outer tibial spurs 2 and 3 shorter than inner. Hind leg much longer that fore and mid leg, but its tibia and tarsus only slightly expanded. Wing membrane without macrotrichia. Sc joining C. R1 short, approximately half of wing length. Rs distinct. Crossvein $\mathrm{m}$-cu present, aligned with $\mathrm{r}-\mathrm{m}$. M1 and M2 fork base and M stem weak or reduced. M3+4 and CuA without a common stem. R1 setose, Sc, R5, M, and CuA bare.

Etymology. The genus name is compound word formed from parisos (Greek

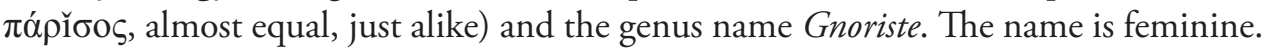

Discussion. Parisognoriste resembles Archaeognoriste from the Upper Cretaceous Burmese amber, but the latter has palpi longer than head height, frons membranous, all longitudinal wing veins setose, Sc ending free, R1 longer than half wing length, M stem and base of M1 and M2 fork distinct and the tibial spurs of equal length. Parisognoriste is similar to Palaeognoriste Meunier but the latter has a long proboscis, one-segmented palpus and club-shaped hind tibia (see also under Phylogenetic analysis).

\section{Parisognoriste eocenica sp. $\mathbf{n}$.}

urn:lsid:zoobank.org:act:FCFCCA94-9A88-4860-BF47-BBA30B83F761

Material examined. Holotype: complete inclusion of female in transparent fossil resin, Oise amber, deposited in the Muséum national d'Histoire naturelle, Paris: MNHN A32914 (PA876).

Type locality: France: Oise department: region of Creil, Chevrière, farm Le Quesnoy, 49¹9.533'N, 2\%40.833'E. Geological horizon: the lowermost Eocene, in amber, c. 53 My, Sparnacian, level MP7 of the mammal fauna of Dormaal (Nel et al. 2004).

Paratypes: two inclusions of females in the same piece of amber (during preparation the piece was cut into two), deposited in the Muséum national d'Histoire naturelle, Paris: MNHN A32914 (PA876).

Morphology. Female. Measurements, mm: Length total 2.22-2.48 (holotype 2.48); wing 1.83-1.91 (holotype 1.91); antenna 0.44-0.49 (holotype 0.49); palpi 0.22 .

Head (Fig. 1) globular with short evenly distributed setae on occiput, face nonsetose. Eye bare, rounded, not emarginated at antennae base, facets round and equal 


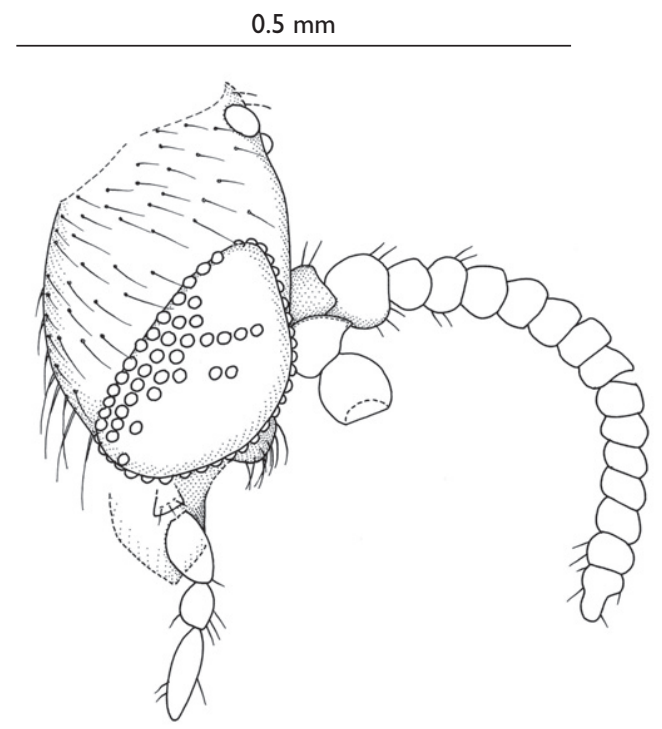

Figure I. Parisognoriste eocenica sp. n., head, lateral.

in size. Ocelli almost in a straight transverse line, the middle slightly smaller than the laterals, distance between lateral ocellus and middle ocellus 2.0x the distance between lateral ocellus and eye margin. Four palpomeres visible: ultimate one elongated, its length $3 x$ the width; penultimate palpomere subglobular, slightly longer than wide; antepenultimate palpomere (the sensilliferous palpomere) about $2 \mathrm{x}$ longer than wide, much wider than the more apical ones; the palpomere basally from the penultimate one short, shorter than the penultimate one. Other mouthparts very short, $-1 / 3$ of head height, labrum dark, triangular; labellum and hypopharynx light, narrow, sharply pointed. Antenna with $2+14$ segments, apical segment secondarily divided into two. Scape and pedicel $2 \mathrm{x}$ wider than flagellomeres, globular. Flagellomeres subcylindrical, ca. $1.5 \mathrm{x}$ broader than long.

Thorax. Scutum uniformly setose with lateral and posterior setae being longer. Scutellum with 10 marginal setae, which are as long and strong as the setae on the posterior part of scutum. Anteprontum with five setae, proepisternum with three setae. Pleural pit inconspicuous. Anepimerone pointed ventrally, touching katepisternum in single point. Laterotergite not produced strongly laterally, bare. Mediotergite non-setose, not convex posteriorly. Metepisternum trapezoidal, with height almost equal to width.

Legs. Procoxa longer than the others. Metacoxa with a row of long posterolateral setae. Protibia about the length of profemur. Tibial organ with a small lobe, but without any distinct setation. Metatibia not conspicuously expanded apically but steadily widening from base to apex, its apical width ca. $2 \mathrm{x}$ the basal width. The vestiture on the apical third of tibia in rows. Spur formula 1:2:2, mesotibia with inner spur $2 x$ the outer, metatibia with inner spur $2.5 \mathrm{x}$ the outer. Claws $1-3$ pointed. 


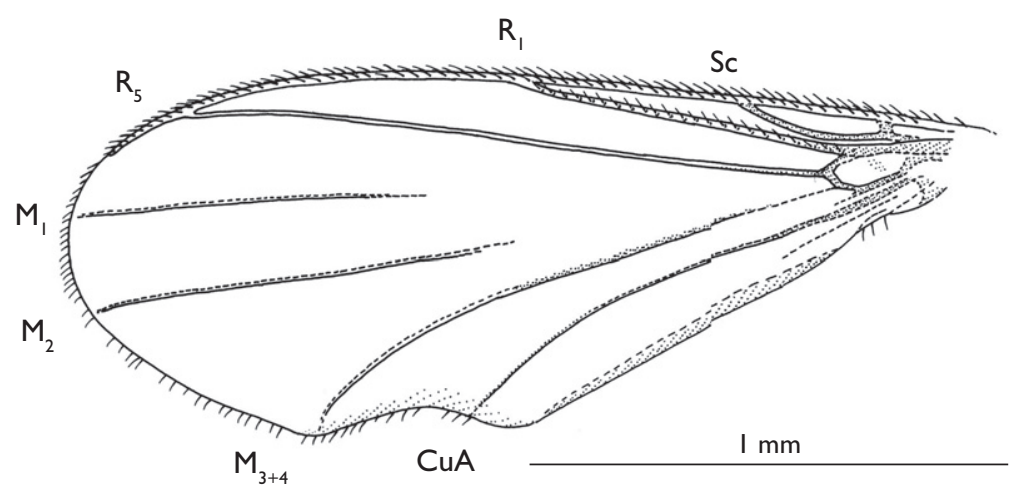

Figure 2. Parisognoriste eocenica sp. n., wing.

Wing (Fig. 2). Costa extending beyond R5 tip at 3/5 distance between tips of R5 and M1. Sc joining C. Rs distinct, oblique. $\mathrm{M}$ stem and base of $\mathrm{M} 1+2$ fork inconspicuous. $\mathrm{M} 3+4$ reduced at base. Transverse vein connecting $\mathrm{Rs}$ and $\mathrm{CuA}$ with a distinct kink at the base of M3+4. R1 with 18-20 dorsal setae, Sc, R5, M, and CuA bare.

Abdomen. Cercus (Fig. 3) two-segmented, basal segment rounded, very short, apical segment oval, its length $2 x$ the width. Sternite 8 wide, rounded apically.

Etymology. The species name is an adjective in the nominative singular, derived from the Eocene period, referring to the temporal distribution of the species.

Discussion. See under Parisognoriste above.

\section{Palaeognoriste Meunier, 1904}

urn:lsid:zoobank.org:act:8E3217CC-0700-4934-8D2F-5C1F93552006

Palaeognoriste Meunier 1904: 87; Meunier 1912: 89; Matile 1990a: 360; Matile 1990b: 366, 373-376, 383, 409, 421, 554; Hoffeins and Hoffeins 1996: 311; Grimaldi and Blagoderov 2001: 55; Hippa et al. 2005: 5, 11; Blagoderov et al. 2009: 32, $33,35,37,45$.

Type species. Palaeognoriste sciariforme Meunier, 1904: 88, by monotypy.

Diagnostic description. Small lygistorrhinid flies. Proboscis medium length, about the length of fore tibia, palpus one-segmented, shorter than labellum. Three ocelli, median ocellus smaller than lateral ocelli. Scutum evenly setose with mediumlength setae, laterotergite bare. Wing venation similar to Parisognoriste but Rs transverse (illustrated in Grimaldi and Blagoderov, 2001: fig. 5a): Sc joining C. R1 short, approximately half of wing length. Rs distinct. R5 setose. Base of fork M1 and M2 incomplete, but traceable. $\mathrm{M} 3+4$ and $\mathrm{CuA}$ without a common stem. Crossvein $\mathrm{m}-\mathrm{cu}$ well developed and aligned with crossvein $\mathrm{r}-\mathrm{m}$. R1 setose, Sc, R5, M, and CuA bare. Hind leg much longer that both fore and mid leg, hind tibia enlarged apically. Tibial 

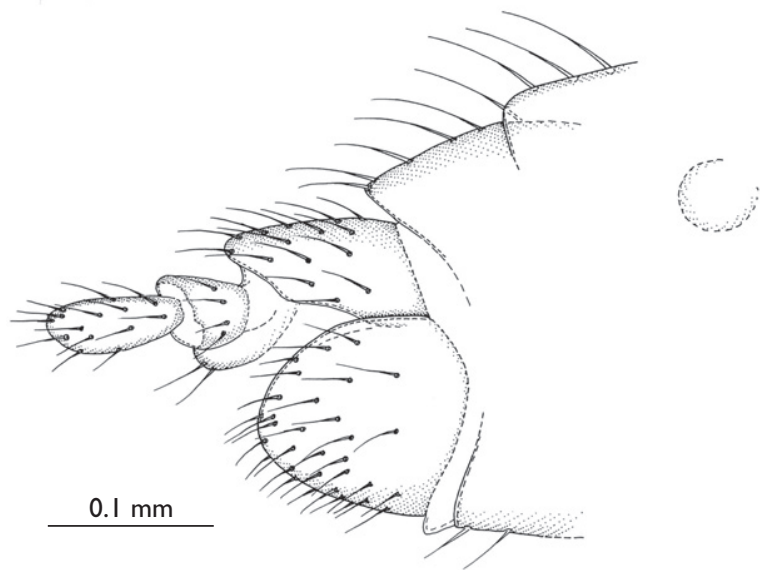

Figure 3. Parisognoriste eocenica sp. n., female genitalia, lateral.

vestiture in rows. Basitarsomere 3 inflated. Male tergite 9 with aggregation of thickened setae at apex.

Discussion. Palaeognoriste is distinguished from all other described fossil taxa of Lygistorrhinidae by the structure of mouthparts and from all recent genera by, for example, a well-developed Rs and r-m (see below under Phylogenetic analysis).

\section{Palaeognoriste sciariforme Meunier, 1904}

urn:Isid:zoobank.org:act:B8A39907-AED8-4DC1-8231-351704E7A84D

Palaeognoriste sciariforme Meunier 1904: 88.

Material examined. Lectotype: male, Baltic amber, Z6630, deposited in Geowissenschaftlisches Zentrum der Georg-August-Universität, Göttingen, Germany, here designated.

Notes. Meunier (1904) described the species based on two specimens, a male and a female, in two separate pieces of amber. The present study revealed that they were not conspecific. For the sake of nomenclatural stability, we designate the male specimen, Z6630, as lectotype. The female specimen, Z5125, most probably belongs to Palaeognoriste affine (see under $P$. affine). Both specimens come from the Königsberg collection of Baltic amber, which was moved after World War II to Geowissenschaftlisches Zentrum der Georg-August-Universität, Göttingen (and currently on loan in the Laboratory of Entomology, Muséum national d'Histoire naturelle, Paris).

Morphology. Male. Measurements, mm: Length total 3.8; wing 2.5; antenna 0.75; labellum 0.95; palpus 0.5.

Head rounded, dichoptic, posteriorly with a row of short $(40 \mu \mathrm{m})$ postoccipital bristles. Ommatidia round, equal in size. Interommatidial setae shorter than ommatidial diameter. Three ocelli, laterals $2 x$ diameter of median, touching eye margin. Clypeus 
triangular, pointed. Palpus one-segmented, $\sim 1 / 2$ length of labellum, with a dorsal row of setae. Antenna 2+14 segmented. Flagellomeres slightly longer than wide.

Thorax: Scutum uniformly setose, with supraalar setae longer than others. Scutellum with four longer subapical marginal setae and irregularly positioned shorter hairs. Antepronotum with three setae. Proepisternum with five setae. Suture between anepisternum and katepisternum distinct. Anepimeron separated from katepisternum with indistinct ridge. Pleural pit distinct, cut into a dorsoventral corner of katepisternum. Laterotergite produced strongly lateroventrally, with a row of seven long setae. Metepisternum trapezoidal, with stronger sclerotized anterior margin, separated from metepimeron with a strong ridge. Mediotergite evenly curved.

Legs: Metacoxa without basolateral depression. Tibial spurs 1:2:2, length 0.1 : $(0.25,0.1):(0.35,0.19)$, outer spur shorter. Tibial and tarsal vestiture in rows. Protibia without tibial organ. Mesotibia with a dorsal row of 7-8 dark setae on apical half, and a dense apical brush of 17-20 dark setae. Mid tarsus with a row of a few dark setae. Metatibia apically and hind basitarsomere entirely swollen. Hind tarsomeres 1-3 with strong dark ventral setae. Claws of fore and mid legs blunt, of hind leg pointed.

Wing: Costa extending 3/5 of distance between tips of R5 and M1. Sc joining C. Rs and $\mathrm{r}-\mathrm{m}$ weakened, but distinct. $\mathrm{M}$ stem and base of $\mathrm{M} 1+\mathrm{M} 2$ fork inconspicuous. $\mathrm{M} 3+4$ base much weakened, $\mathrm{M} 3+4$ and $\mathrm{CuA}$ without common stem. Distance between apices of R5, M1, M2, M3+4 and CuA: 2.4: 1.5: 1.2: 1.8: 1.0. M1 slightly arched, M2 curved backwards apically. R1 setose, Sc, R5, M, CuA bare. Wing membrane without macrotrichia.

Abdomen: Tergite 9 broadly curved posteriorly, with numerous short dark spines directed posteriorly and longer light setae directed ventrally at apex. Gonostyli narrow, flattened, $4 \mathrm{x}$ longer than wide, each with two stout apical teeth and long dorsal mesial setae. Gonocoxite (Fig. 4) in lateral view with an obtuse angle on dorsal edge, a setae near the angle and two long setae near the base on gonostylus; covered with long setae ventrally.

\section{Palaeognoriste affine Meunier, 1912}

urn:lsid:zoobank.org:act:6F42E20F-5073-473E-8463-38881FB76D10

Palaeognoriste affine Meunier 1912: 89.

Material examined. Lectotype: male, Baltic amber, G1848 (BST.03.382), deposited in the Geowissenschaftlisches Zentrum der Georg-August-Universität, Göttingen, Germany; here designated.

Paralectotype: female, Baltic amber, G1848 (BST.03.382), deposited in the Geowissenschaftlisches Zentrum der Georg-August-Universität, Göttingen, Germany; here designated.

Other material: female, Baltic amber, Z5125 (syntype of P. sciariforme), deposited in the Geowissenschaftlisches Zentrum der Georg-August-Universität, Göttin- 


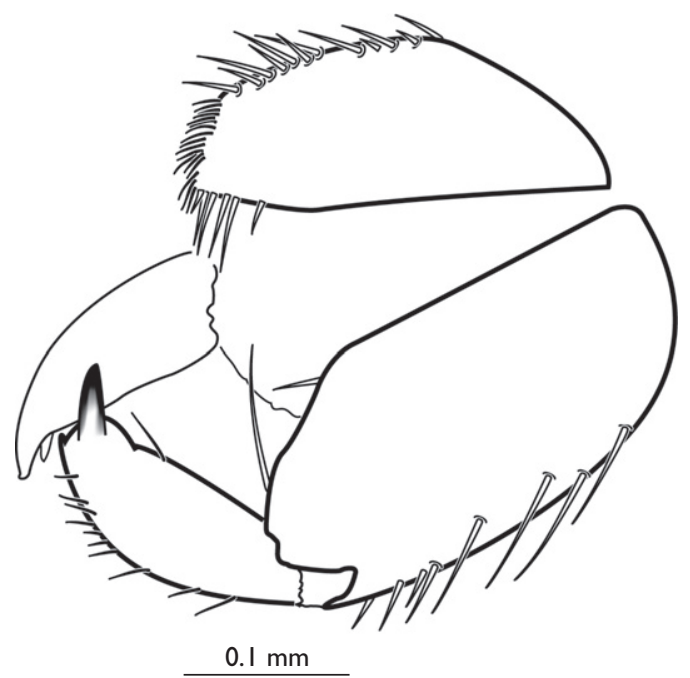

Figure 4. Palaeognoriste sciariforme Meunier, 1904, male genitalia, lateral.

gen, Germany (currently on loan in the Laboratory of Entomology, Muséum national d'Histoire naturelle, Paris).

Notes. Meunier (1912) described P. affine from a male and a female in copula. We here designate the male as lectotype and the female as paralectotype.

Morphology. Male. Measurements, mm: length total 3.8; wing 2.5; antenna 0.75; labellum 0.95; palpus 0.5.

Head rounded, dichoptic. Ommatidia densely set, almost hexagonal, becoming slightly smaller dorsally. Interommatidial setae inconspicuous. Three ocelli present, diameterer of medial one $0.6 \mathrm{x}$ of the lateral ones, lateral ocelli touching eye margin. Antennae 2+14 segmented; flagellomeres as wide as long, with one or two short dorsal setae and two short ventral spines each. Scape small, as long as wide, trapezoidal. Pedicel globular, slightly wider than flagellum. Clypeus triangular, pointed. Palpus onesegmented, 0.56x length of labellum, with a row of dorsal setae. Labellum lanceolate at apex. Hypopharynx wide and strongly sclerotized.

Thorax. Scutum uniformly setose with supraalar setae slightly longer than others. Antepronotum and proepisternum with 7-8 short setae each. Suture between anepisternum and katepisternum distinct. Pleural pit inconspicuous. Laterotergite produced strongly lateroventrally, with a row of five long setae postero-ventrally. Metepisternum trapezoidal, separated from metepimeron with a strong ridge.

Legs. Procoxa and mesocoxa with a few anteroapical setae. Metacoxa with deep lateral depression and 2 long posterolateral setae on apical 1/3. Tibial spurs 1:2:2, length 0.08 : $(0.17,0.11):(0.25,0.12)$, outer spur shorter. Protibia without tibial organ. Tibial and tarsal vestiture in rows. Metatibia gradually expanding apically, with a row of 10 long dorso-lateral setae and 7-8 light apical inner setae not arranged in dense brush. First tarsomere of metatarsus inflated, with nine short setae in lateral row and 14 in ventral. Claws of fore leg blunt, of mid and hind legs pointed. 


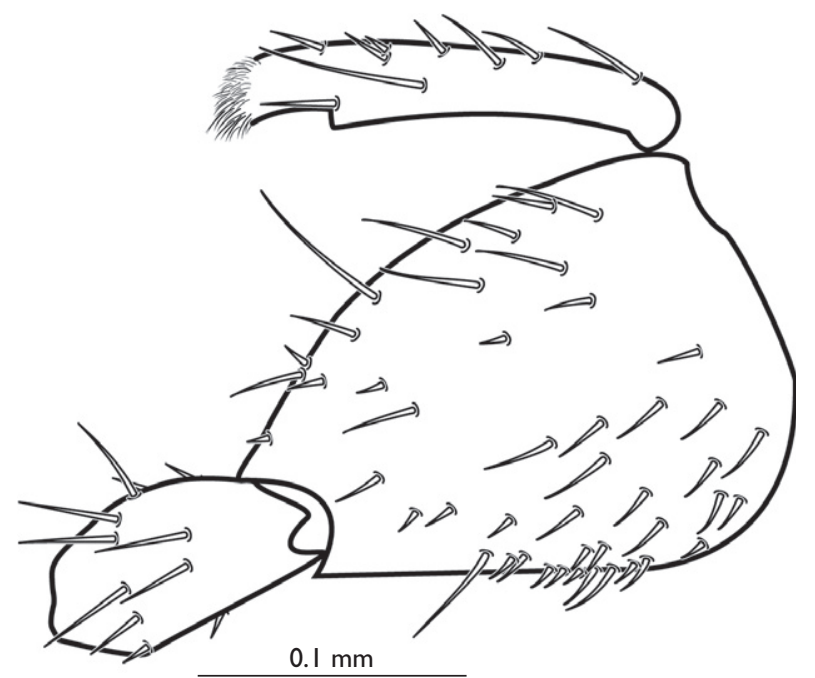

Figure 5. Palaeognoriste affine Meunier, 1912, male genitalia, lateral.

Wing. Costa extends beyond R5 on $0.5 \mathrm{x}$ distance between R5 and M1. Sc short, joins Costa. Rs, r-m, M stem inconspicuous. Base of M1 and M2 fork traceable. M1 slightly arched, M2 almost straight apically. Ratio of distances between R1, R5, M1, M2, M3+4 and CuA 2.0:1.5:0.8:1.6:1.0.

Abdomen. Tergite 9 with a dense patch of short setae apically, without longer light setae. Dorsal margin of gonocoxites in lateral view evenly curved. Gonocoxites and gonostyli covered with long setae laterally; dorsal edge evenly curved (Fig. 5).

Female 1 (paralectotype). Measurements, mm: length total 3.8, wing 2.5, antenna 0.75 , proboscis 0.95 , palpus 0.5 . As male, except: Compound eye smaller, not reaching lateral ocelli. All ommatidia equal in size to dorsal ommatidia of male. Interommatidia setae slightly longer than diameter of ommatidia. Ocelli in wide triangle, diameter of lateral ocellus $2 \mathrm{x}$ the medial ocellus, distance from lateral ocellus to eye slightly longer than to medial ocellus. Scape a little smaller than pedicel, trapezoidal. Pedicel wide, trapezoidal, $2 x$ the width of flagellum; flagellomeres slightly shorter than wide, with numerous irregularly placed setae. Palpus $0.53 x$ the labellum. Labellum widely rounded apically. Hypopharynx weak. Scutellum with 4 pairs of long subapical marginal setae. Antepronotum and proepisternum with 3-4 long setae each. Procoxa with long anterior setae, mesocoxa and metacoxa with long lateral setae on apical half. All claws pointed. Setae on fore basitarsomere shorter and less numerous than in male. Hind tibia with a 13-15 thin dorsal setae. Tibial spur lengths 0.11 : $(0.22,0.12)$ : $(0.27$, $0.13)$. Cercus two-segmented, basal segment globular, apical obovate, length $2 x$ the basal one, with a few short setae laterally and ventrally.

Female 2 (syntype of $P$. sciariforme, Z5125, see under $P$. sciariforme). Measurements, mm: length total 2.9; wing 2.0; antenna 0.55; proboscis 0.75; palpi 0.4. Lateral ocelli almost touching compound eye. Flagellomeres shorter than wide. Pedicel large, round. Hind tibia with an anteriodosral row of seven thin dark setae. Hind basitar- 


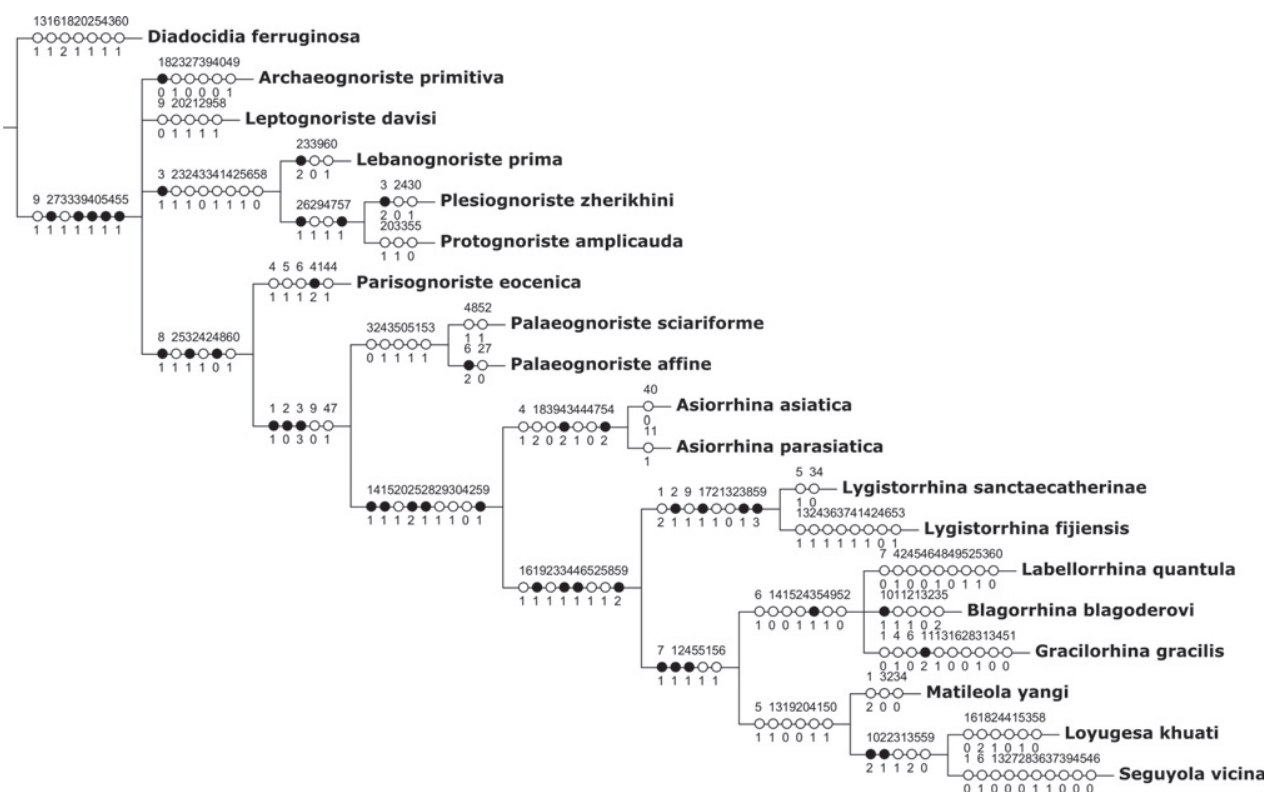

Figure 6. Strict consensus cladogram of four most parsimonious cladograms (176 steps, $\mathrm{CI}=0.43, \mathrm{RI}=$ 0.57). Black dots = unique character changes, open circles = homoplastic changes.

somere with a few weak dark setae. Laterotergite with four long setae. M1 arched, M2 almost straight apically. Base of M1 and M2 fork apparent, slightly proximad of level of R1 tip. Antepronotum with 4-5 short setae, proepisternum with seven setae. All claws pointed. Cercus two-segmented, length of apical segment $2 \mathrm{x}$ the basal one, basal segment trapezoidal, apical elliptic with numerous long setae at apex.

Discussion. $P$. affine differs from $P$. sciariforme in having the male mid tarsal claws pointed, not blunt, base of $\mathrm{M}$ fork weak but distinguishable, $\mathrm{M} 2$ straight, not curved, at apex, weaker and fewer ventral setae on hind tarsomeres 1 and 2 (11 and four pairs contra 16 and six), dorsal margin of gonocoxites evenly curved, gonocoxites setose dorsally as well as ventrally, tergite 9 without longer apical setae. It is possible that the female specimen Z5125 is not conspecific with the paralectotype of P. affine. However, we consider the differences rather small, and they may be a result of post-embedding distortion, and until new material become available we prefer to refer the specimen to $P$. affine.

\section{Phylogenetic analysis}

Phylogenetic analysis was based on characters from Blagoderov et al. (2009). The data matrix was created and edited in Mesquite ver. 2.6 (Maddison and Maddison 2009) and analysed in WinNona version 2.0 (Goloboff 1999). The search parameters used were 'hold100000; hold/1000; mult*1000; mult*max'. All characters were equally weighted and multistate characters treated as non-additive. Cladograms and character distribution were analysed in WinClada verson 1.00.08 (Nixon 2002). 
Cladistic analysis yielded four equally most parsimonious cladograms of 174 steps $(\mathrm{CI}=0.44, \mathrm{RI}=0.58)$. The strict consensus tree (Fig. 6) is congruent with previous studies (Hippa et al. 2005, Blagoderov et al. 2009). Parisognoriste forms a monophyletic group together with the clade comprising Palaeognoriste + recent Lygistorrhinidae; this group has the following synapomorphies: medial ocellus smaller than lateral (char. 8), proximal position of Rs base (char. 25), and non-setose R5 (char. 32). The taxa of the clade of Palaeognoriste + recent Lygistorrhinidae have long proboscis (char. 1), maxillary palpus shorter than labellum (char. 2), one palpomere (char. 3), ocelli almost in transverse line (char. 9), and hind tibiae club-shaped (char. 47). Although both species of Palaeognoriste form a well-defined clade, the genus has no unambiguous synapomorphies, all three supporting characters undergoing similar changes elsewhere: R5 setose (char. 35); basitarsomere 3 inflated (char. 50); tarsal claws 1 blunt (char. 51); Rs base transverse (in Parisognoriste and some Cretaceous taxa - oblique).

Parisognoriste and Palaeognoriste belong to the base of a clade of modern Lygistorrhinidae, different from the Mesozoic taxa. This replacement corresponds to significant changes of environment in the Upper Cretaceous and Palaeocene. Thus, we can hypothesise that gradual increase on length of the proboscis in Cainozoic taxa of Lygistorrhinidae reflects wider distribution of nectar-bearing angiosperms in Palaeocene-Eocene.

\section{Acknowledgements}

This research received support from the SYNTHESYS Project (http://www.synthesys.info) which is financed by European Community Research Infrastructure Action under the FP6 "Structuring the European Research Area" Programme (projects No. SE-TAF 5109, FR-TAF-3001). Prototype of the interface between Scratchpads and ZooKeys journal allowing rapid publication of taxonomic papers was created within the EDIT IRG grant "Streamlining Fungus Gnats Taxonomy". Authors are grateful to Dr Ian Kitching of the Department of Entomology, the Natural History Museum, London for valuable comments and checking English language of the manuscript.

\section{References}

Blagoderov V, Brake I, Georgiev T, Penev L, Roberts D, Rycroft S, Scott B, Agosti D, Catapano T, Smith VS (2010) Streamlining taxonomic publication: a working example with Scratchpads and ZooKeys. ZooKeys 50: 17-28. doi: 10.3897/zookeys.50.539

Blagoderov V, Hippa H, Ševč́k J (2009) Asiorrhina, a new Oriental genus of Lygistorrhinidae (Diptera: Sciaroidea) and its phylogenetic position. Zootaxa 2295: 31-45. http://www. mapress.com/zootaxa/2009/f/z02295p045f.pdf

Goloboff P (1999) NONA, version 2.0. Tucuman, Argentina. Fundacion e Instituto Miguel Lillo. 
Grimaldi D, Blagoderov V (2001) A new genus of Lygistorrhinidae from Vietnam (Diptera: Sciaroidea), and phylogenetic relationships in the family. Studia Dipterologica 8: 43-57.

Hippa H, Mattsson I, Vilkamaa P (2005) New taxa of the Lygistorrhinidae (Diptera: Sciaroidea) and their implications for a phylogenetic analysis of the family. Zootaxa 960: 1-34. http://www.mapress.com/zootaxa/2005f/z00960f.pdf

Hoffeins C, Hoffeins HW (1996) Palaeognoriste sp. Ungewöhnliche Pilzmücke im Baltischen Bernstein. [Palaeognoriste sp., an unusual fungus gnat in Baltic amber.]. Fossilien 13: 311-314.

Maddison W, Maddison D (2009) Mesquite: a modular system for evolutionary analysis. Version 2.6. http://mesquiteproject.org

Matile L (1990a) Les Lygistorrhinidae de la region afrotropicale (Diptera: Mycetophiloidea). Annales de la Société Entomologique de France 26: 359-370.

Matile L (1990b) Recherches sur la systématique et l'évolution des Keroplatidae (Diptera, Mycetophiloidea). Mémoires du Muséum national d'Histoire naturelle, serie A Zoologie 148: $1-682$.

Meunier F (1904) Monographie des Cecidomyidae, des Sciaridae, des Mycetophilidae et des Chironomidae de l'ambre de la Baltique < part>. Annales de la Société Scientifique de Bruxelles 28: 12-92. http://www.biodiversitylibrary.org/bibliography/8565

Meunier F (1912) Un nouveau Mycetophilidae de l'ambre de la Baltique <Dipt.>. Bulletin de la Société Entomologique de France 1912: 88-90.

Nel A, De Ploëg G, Menier J-J, Waller A (2004) The French ambers: a general conspectus and the Lowermost Eocene amber deposit of Le Quesnoy in the Paris Basin. Geologica Acta 2: 3-8. http://www.geologica-acta.com/MostrarAbstractAC.do?abstract=gav0201a02

Nel A, Prokop J, De Ploëg G, Millet J (2005) New Psocoptera (Insecta) from the Lowermost Eocene amber of Oise, France. Journal of Systematic Palaeontology 3: 371-391. doi: $10.1017 /$ S1477201905001598

Nixon KC (2002) Winclada, Version 1.00.08. Ithaca, New York. Published by author.

Penev L, Agosti D, Georgiev T, Catapano T, Miller J, Blagoderov V, Roberts D, Smith VS, Brake I, Rysrcroft S, Scott B, Johnson NF, Morris RA, Sautter G, Chavan V, Robertson T, Remsen D, Stoev P, Parr C, Knapp S, Kress J, Erwin T (2010) Semantic tagging of and semantic enhancements to systematics papers: ZooKeys working examples. ZooKeys 50: 1-16. doi: $10.3897 /$ zookeys.50.538

\section{Supplementary material}

The Scratchpad version of this publication is available on the Fungus Gnats Online website at: http://sciaroidea.info/node/44428

Character matrix used for the analysis is available on Fungus Gnats Online website at: http://sciaroidea.info/sites/sciaroidea.info/files/Parisognoriste_matrix.txt

Additional images:

Parisognoriste eocenica http://sciaroidea.info/taxonomy/47895

Palaeognoriste affine http://sciaroidea.info/taxonomy/41600

Palaeognoriste sciariforme http://sciaroidea.info/taxonomy/41601 